\title{
Research on the Methods of Releasing the Capacity of Railway for Transferring Freight Flow from Road to Railway
}

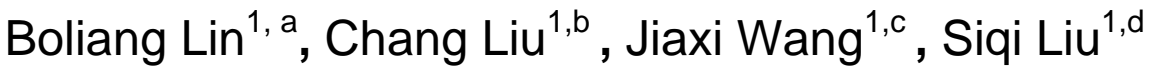 \\ ${ }^{1}$ School of Traffic and Transportation, Beijing Jiaotong University, Beijing 100044, China \\ abllin@bjtu.edu.cn, b14114241@bjtu.edu.cn, wangiiaxi@bjtu.edu.cn, ${ }^{d} 15114206 @$ bjtu.edu.cn
}

Keywords: carbon emission; low-carbon transportation system; freight flow assignment; damping coefficient adjustment.

Abstract. This paper firstly analyses the necessity of constructing low-carbon emission system in China and put forward the concept of reducing carbon emission by transferring freight flow from road to railway. The methods of releasing the capacity of railway are studied emphatically, including the cost of freight flow transferring, the principle and operating program of damping coefficient adjustment and specific route adjustment. Finally, a case study was designed to show the application of the theory.

\section{Introduction}

With the development of economy, environmental problem has become increasingly apparent. In recent years, the continuous haze weather in China has done great harm to people's life. Air pollution has become the most severe challenge which Chinese government faces.

Among the factors that cause air pollution, transportation emission occupies a large proportion. Therefore, developing low carbon transport system is the key point of China's transportation industry energy-saving and emission reduction work, and it is also an important part of environmental governance in China.

According to statistics, most of the carbon emissions come from road and rail transport, and carbon emission from highway transportation per ton- $\mathrm{km}$ is much more than that of railway transport. Therefore, considering the energy conservation and emissions reduction as well as the technical economic characteristics of highway and railway transportation, the long distance transportation of bulk cargo should be delivered by railway, and highway should mainly undertake the transport of short distance and small batch. However, in northwestern China, a large amount of long distance coal transportation is undertaken by road. This will not only make the carbon emissions of transportation increase greatly, but also cause serious congestion and road damage. This condition is unreasonable when considering environment, safety and economy. So, transferring the long distance bulk goods from road to railway is an important part of the development of low-carbon transport.

To transfer goods from road to railway, there needs enough transport capacity on railway. When the capacity of the railway section is insufficient, two measures can be taken to release enough capacity to receive freight flow from the road. One of them is constructing parallel high-speed railway to transfer the passenger flow to it and the other one is transferring a certain amount of freight flow to other railway line. This paper mainly focuses on the method of transferring freight flow to other railway during the traffic volume planning stage.

\section{Research on the Methods of Transferring Freight Flow}

Introduction on the Methods of Transferring Freight Flow. Transferring freight flow is mainly based on two methods. One of them is damping coefficient adjustment and the other one is specific route adjustment (specific route refers to a certain route that certain trains must travel along, even if it is not the shortest one for the trains). The results of the two methods are to transfer part of freight flow to other routes so that the capacity of a certain section can be released. The theory of the two methods and the relationship between transferred freight flow volume and cost will be introduced emphatically. 
Railway Freight Flow Transferring Methods Based on Damping Coefficient Adjusting. The damping coefficient adjustment is applied to traffic flow assignment which is based on generalized shortest route. The method changes the flow assignment results by setting damping coefficient which can adjust the generalized mileage of a certain segment.

For example, there is a railway segment $a$ in parallel with a highway and part of the capacity need to be released in order to receive the freight flow from the parallel highway. In order to introduce the theory clearly, the variables are denoted as follows:

$l_{a}$ — the mileage of segment $a$;

$\beta$ — the damping coefficient of segment $a$;

$L_{a} \longrightarrow$ the generalized mileage of segment $a, L_{a}=\beta \cdot l_{a}, L_{a}-l_{a}=(\beta-1) l_{a}$;

$f_{i}$ - the index of the freight flows which go through segment $a$ along their shortest route, $i=1,2,3, \cdots, n$;

$m_{i} \longrightarrow$ the volume of each freight flow, $i=1,2,3, \cdots, n$;

$\Delta l_{i}$ — the mileage increment of secondary shortest route comparing with the shortest route, assuming that $\Delta l_{1} \leq \Delta l_{2} \leq \Delta l_{3} \leq \cdots \leq \Delta l_{n-1} \leq \Delta l_{n}$.

When $L_{a}-l_{a}<\Delta l_{1}$ namely $\beta<\frac{\Delta l_{1}}{l_{a}}+1$, there is no freight flow transferring and the turnover volume doesn't change.

When $\Delta l_{1} \leq L_{a}-l_{a}<\Delta l_{2}$ namely $\frac{\Delta l_{1}}{l_{a}}+1<\beta \leq \frac{\Delta l_{2}}{l_{a}}+1, f_{1}$ will transfer to its secondary shortest route, the turnover volume will increase by $m_{1} \Delta l_{1}$;

When $\Delta l_{2} \leq L_{a}-l_{a}<\Delta l_{3}$ namely $\frac{\Delta l_{2}}{l_{a}}+1<\beta \leq \frac{\Delta l_{3}}{l_{a}}+1, \quad f_{1}$ and $f_{2}$ will transfer to its secondary shortest route, the turnover volume will increase by $m_{1} \Delta l_{1}+m_{2} \Delta l_{2}$;

With $\beta$ increasing, $f_{1}, f_{2}, \cdots, f_{n}$ will transfer to their secondary shortest routes successively so that the capacity of segment $a$ will be released. But this will cause the increase of the turnover volume.

Railway Freight Flow Transferring Methods Based on Specific Route Adjusting. The main idea of specific route adjustment is setting specific nodes for certain freight flow so that the freight flow will transfer to specific routes. As shown in Fig. 1, it is assumed that there are 2 flows of freight travel through BC segment (the solid line of freight flow 1 and freight flow 2). Now this segment should release a certain amount of capacity to receive freight flow from the road. According to the structure of the network, assign freight flow 1 to the segment between $\mathrm{G}$ and $\mathrm{H}$. Then calculate the shortest route of $\mathrm{AG}, \mathrm{GH}$ and $\mathrm{HE}$ respectively. Thus, the specific route can be achieved, as the dotted lines shown in Fig. 1. In this way the capacity of BC segment can be released.

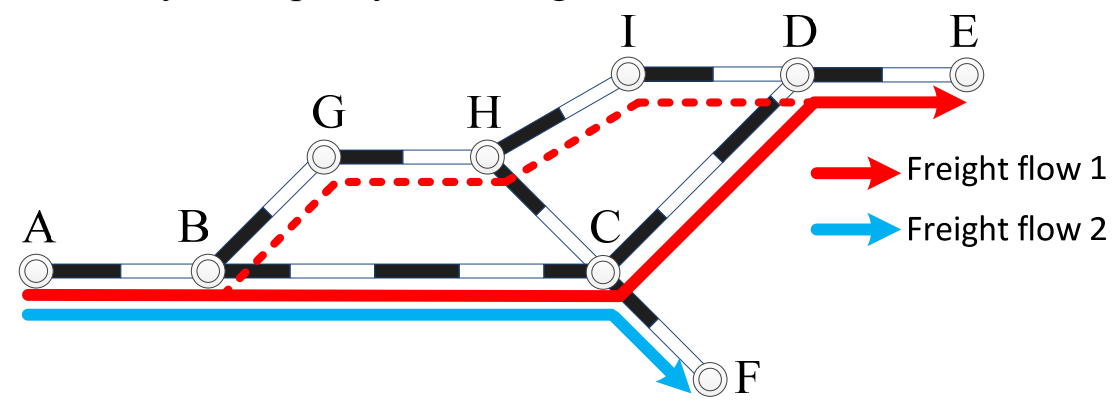

Fig. 1 Example of Setting Specific Route 


\section{Case Study}

Part of railway network and highway in northern China is shown in Fig.2 (The orange line represents highway and others represent railway). Every year, plenty of coal is delivered from $\oslash$ through the highway to $\mathrm{d}$ and the areas along it. This would make the highway overload and cause serious air pollution including carbon emission. So, we need to transfer the coal flow from the highway to the railway which is parallel with it. From Fig. 2 we can know that the route $\oslash \rightarrow(3) \rightarrow \rightarrow(5 \rightarrow(\rightarrow)$ is suitable.

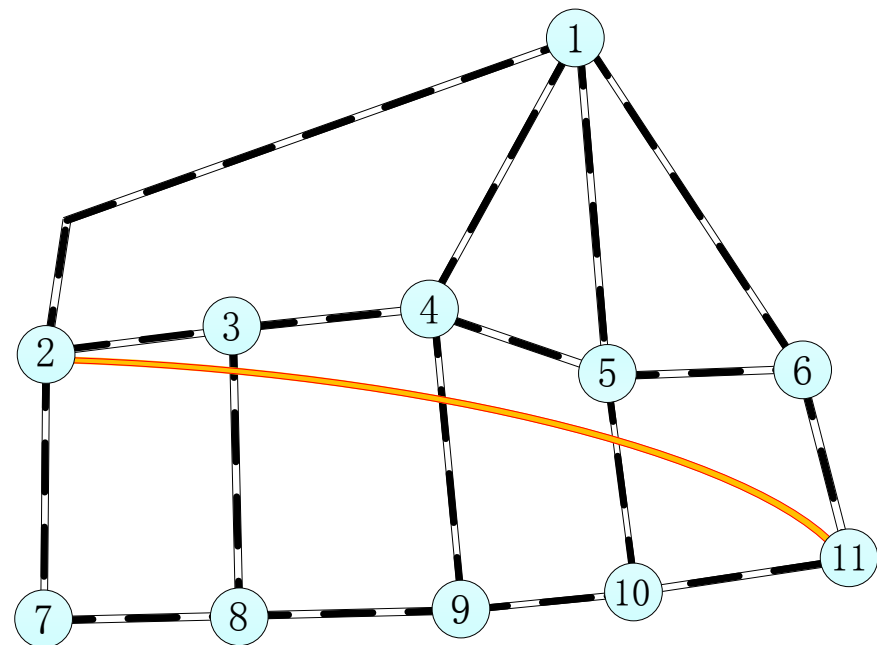

Fig. 2 Part of Railway Network and Highway in Northern China

The load of freight flow (10000t/year) on the railway network is shown in Fig.3. In the figure we can know that the capacity of segment $(3) \rightarrow \oplus$ has its limit. Therefore, some freight flow should be transfer to other route to release the capacity of $(3) \rightarrow \oplus$. Assuming that there are 30 million tons of freight flow should be transferred per year, we adjust the flow assignment result by adjusting the damping coefficient of segment (3) $\rightarrow \oplus$ first. The damping coefficient increases by step of 0.1 from 1 to 2. As it increases, the volume of freight flow and the amount of OD pairs will decline, but the turnover volume of the whole railway network will increase. The output data is shown in Fig.4.

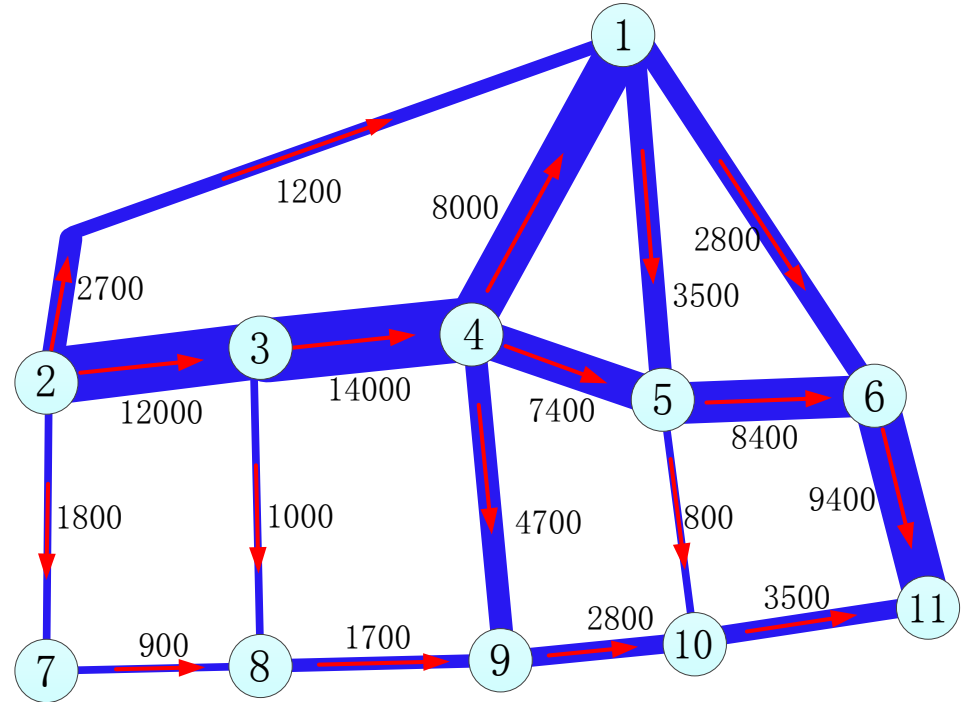

Fig. 3 Load of Freight Flow on Railway Network 


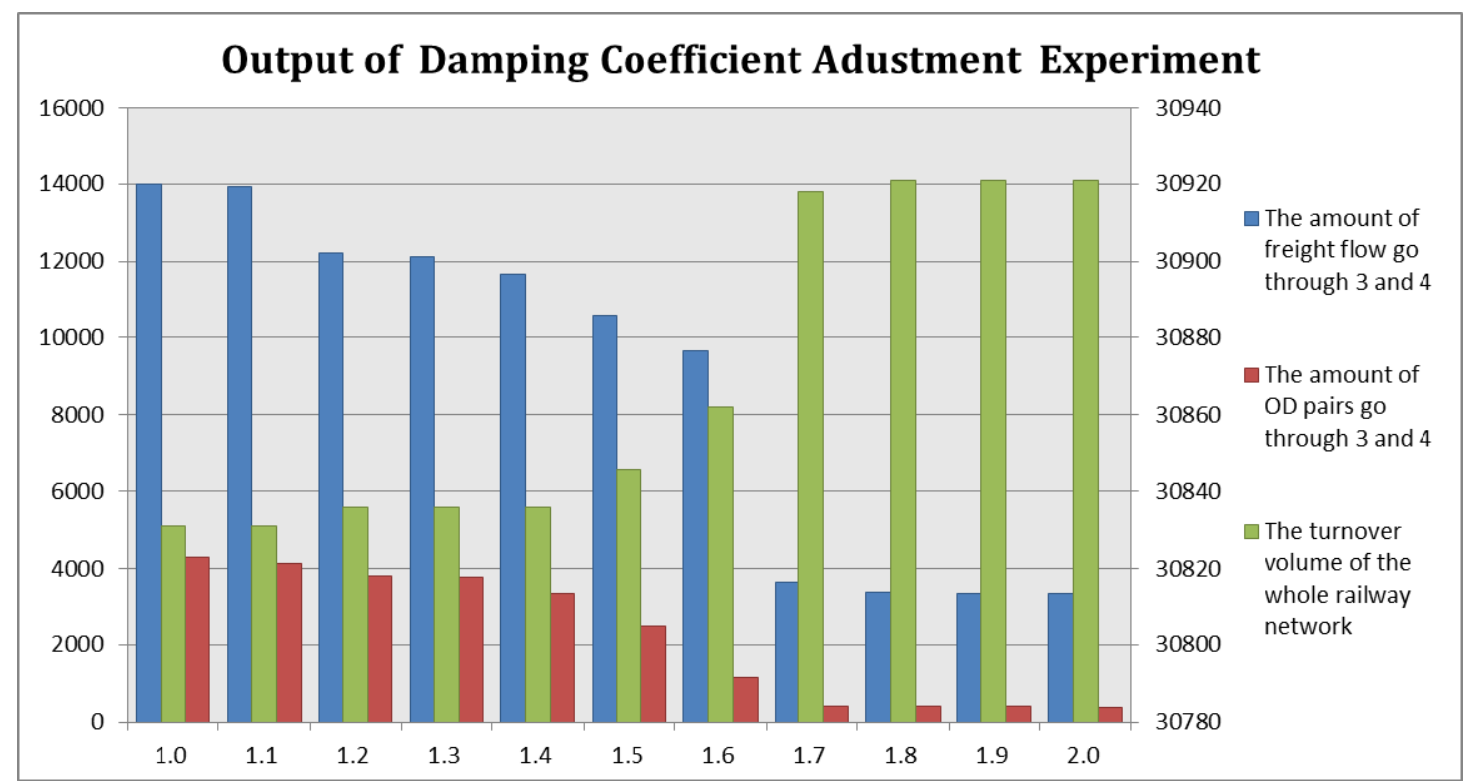

Fig. 4 Output of Damping Coefficient Adjustment Experiment

When $\beta=1.4$, the amount of the freight flow is 116.69 million tons, namely 23.31 million tons of freight was transferred to other routes. When $\beta=1.5$, the amount of the freight flow is 105.85 million tons, namely 34.15 million tons of freight was transferred to other routes. To ensure there are 30 million tons of freight transferred to other routes, we should set $\beta=1.4$ and select 6.69 million tons of freight and set specific route for them. According to the structure of the railway network and the utility ratio of the segments, the route $\delta \rightarrow \delta \rightarrow \delta \rightarrow B \rightarrow b \rightarrow b$ should be set as the specific route. Therefore, the freight flow on the route $\beta \rightarrow \delta \rightarrow \oint \rightarrow \delta \rightarrow \sigma \rightarrow b$ can be transferred to the specific route. So, some OD pairs with total freight volume of 6.7 million tons which originally go through $\beta$ and $\mathrm{b}$ is selected and assigned to the specific route. So, the total amount of freight transferred from segment $\Theta \rightarrow €$ to other routes reaches 30 million tons. The total turnover volume increases by 1.5 billion $t \cdot \mathrm{km}$. The load of the railway network is shown in Fig.5.

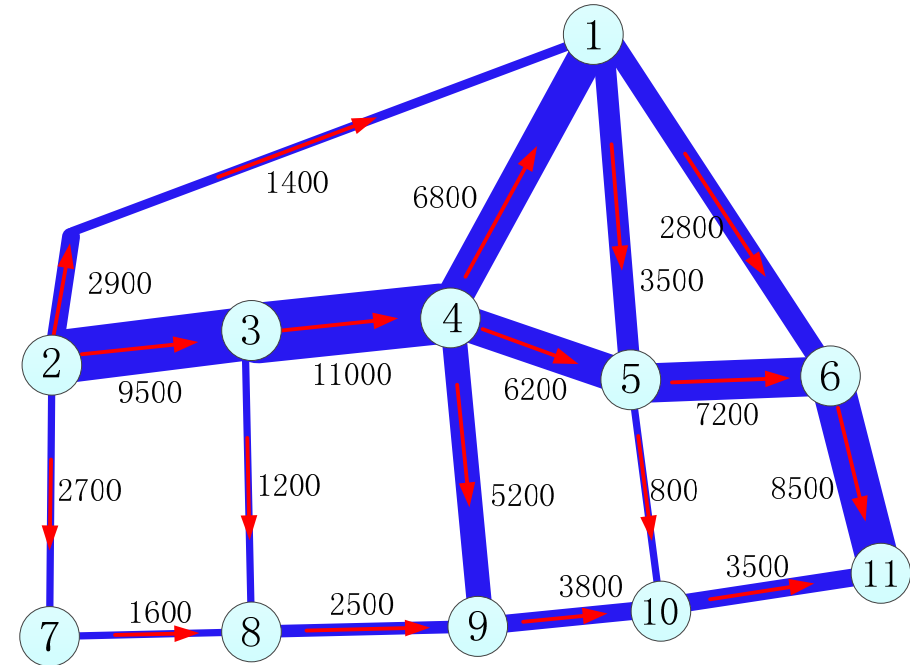

Fig. 5 The Load of the Network After Adjusting

In this way, there are at least 30 million tons of freight can be transferred from highway to railway. According to statistics, the carbon emission of per $t \cdot \mathrm{km}$ on highway and railway are $0.13 \mathrm{~kg}$ and $0.0064 \mathrm{~kg}$ respectively. The length of the highway from $\beta \rightarrow b$ is $440 \mathrm{~km}$. So, if the 30 million tons of freight per year can all be transferred to railway, the carbon emission of the total transportation 
system can reduce $1.71 \times 10^{6} t\left(3 \times 10^{7} \times 440 \times 0.13-1.5 \times 10^{9} \times 0.0064=1.71 \times 10^{9} \mathrm{~kg}=1.71 \times 10^{6} \mathrm{t}\right)$ in one year. This will make great contribution to low-carbon transportation system.

\section{Conclusion}

This paper studies the theory and method of railway channel capacity release based on the damping coefficient adjustment and specific route adjustment and demonstrates the principle of the two methods. A case study is made according to the reality of railway transportation in China. The proposed method is applied successfully to get a reasonable flow transfer plan, thus the rationality and feasibility of the methods are proved. The result provides basis for the research on carbon tax policy and the freight flow assignment in integrated transportation network.

\section{Acknowledgements}

This work was financially supported by the Chinese Natural Science Foundation (51178031) and (51378056).

\section{References}

[1] Saija S, Romano D. A methodology for the estimation of road transport air emissions in urban areas of Italy[J]. Atmospheric Environment, 2002,36(34):5377-5383.

[2] Weijian Chen. Scheme Design of the Transfer of Freight flow for United Transportation of Railways and Highways based on the Carbon Emissions [D].Beijing: Beijing Jiaotong University,2015.

[3] Patterson Z, Ewing G O, Haider M. The potential for premium-intermodal services to reduce freight CO 2 emissions in the Quebec City-Windsor Corridor[J]. Transportation Research Part D, 2008,13(1):1-9.

[4] Liao C, Tseng P, Lu C. Comparing carbon dioxide emissions of trucking and intermodal container transport in Taiwan[J]. Transportation Research Part D: Transport and Environment, 2009,14(7):493-496.

[5] Haghani, A.E. Formulation and Solution of a Combined Train Routing and Makeup, and Empty Car Distribution Model. Transportation Research, Vol. 236, 1989, pp.433-452.

[6] Cordeau, J. F., Toth, P., and Vigo, D. A Survey of Optimization Models for Train Routing and Scheduling. Transportation Science, Vol. 32, No. 4, 1998, pp. 380-404.

[7] Yu Zhao, and Shide Zheng. Optimization and Regulation of Wagon Flow Organization in Railway Network. Journal of Northern Jiaotong University, Vol. 14, No. 4, 1990, pp. 74-80.

[8] He K, Huo H, Zhang Q, et al. Oil consumption and $\mathrm{CO}_{2}$ emissions in China's road transport: current status, future trends, and policy implications[J]. Energy policy, 2005,33(12):1499-1507.

[9] Cosgrove D. Long-term emission trends for Australian transport: 31st Australasian Transport Research Forum, Gold Coast, 2008[C].

[10] Wang T, Li H, Zhang J, et al. Influencing Factors of Carbon Emission in China's Road Freight Transport[J]. Procedia-Social and Behavioral Sciences, 2012,43:54-64.

[11] Ishfaq R, Sox C R. Hub location-allocation in intermodal logistic networks[J]. European Journal of Operational Research, 2011,210(2):213-230.

[12] Xumin, G., Chao, Z., and Yan, G. D-GUB Algorithm of Freight Flow Assignment Model in Railway Network. Journal of the China Railway Science,Vol. 17, No. 4, 1995, pp. 1-7. 